\title{
CONVERGÊNCIAS TEÓRICAS ENTRE A GOVERNANÇA CORPORATIVA E A SUSTENTABILIDADE SOB A PERSPECTIVA DA LEGITIMIDADE
}

\author{
Rodrigo Moreira Casagrande \\ Doutorando em Administração pela Fundação Universidade Regional de Blumenau -FURB \\ Sanduíche pela Université de Montreal - UdeM \\ Professor da Faculdade Meridional - IMED \\ rodrigomcasagrande2013@gmail.com
}

\author{
Eduardo Eduardo Facin Lavarda \\ Doutor em Contabilidade pela Universitat de València - UV - Homologado USP \\ Professor do Departamento de Ciências Contábeis da UFSC \\ elavarda@gmail.com
}

\begin{abstract}
RESUMO
Este trabalho, de cunho teórico, tem como principal objetivo analisar as convergências teóricas entre a governança corporativa e a sustentabilidade, tendo como sustentação a teoria institucional. Para tanto, inicialmente analisa os aspectos da legitimidade, que ocupam um papel de protagonismo na teoria institucional. A seguir, explora a temática da governança corporativa e sua inerente busca pela transparência e pela mitigação da assimetria de informações. Prosseguindo, é aborda a sustentabilidade sob a perspectiva do triple bottom line, que considera, conjuntamente, as dimensões econômica, social e ambiental. Por fim, discorre sobre a relação entre governança corporativa e sustentabilidade, considerando as evoluções históricas dos temas. Os resultados da pesquisa demonstram que a governança corporativa recebe alta prioridade na agenda dos formuladores de políticas organizacionais, investidores e acadêmicos, indicando que a ligação desta temática com a busca por legitimidade e a sustentabilidade mostra-se um campo profícuo para a produção de pesquisas acadêmicas.
\end{abstract}

Palavras-chave: Governança corporativa; Legitimidade; Sustentabilidade; Teoria Institucional.

\section{THEORETICAL CONVERGENCE BETWEEN CORPORATE GOVERNANCE AND SUSTAINABILITY IN THE PERSPECTIVE OF LEGITIMACY}

\section{ABSTRACT}

The main objective of this study is to analyze the theoretical convergence between corporate governance and sustainability issues, using the Institutional Theory as reference. Thus, this paper initially examines the issue of legitimacy, which holds a prominent position in Institutional Theory. After that, this research analyzes the issue of corporate governance and its inherent quest for transparency and mitigation of information. Continuing, we discuss sustainability from the triple bottom line perspective, which considers economic, social and environmental dimensions. Finally, this paper approaches the relationship between corporate governance and sustainability, considering the historical developments of the subjects. The results demonstrate that corporate governance has been receiving high attention on the agenda of organizational policy makers, investors and academics, indicating that the connection between corporate governance, legitimacy and sustainability proves to be a fruitful field for academic research.

Keywords: Corporate governance; Institutional Theory; Legitimacy; Sustainability. 


\section{INTRODUÇÃO}

Sob uma perspectiva sociológica de interpretação da teoria institucional, trabalha-se com o pressuposto de que a realidade é uma construção fundamentada, sobretudo, em sistemas de crenças e conhecimento culturalmente situados (Berger \& Luckmann, 1974). Além disso, considera-se que as organizações não competem apenas por recursos e clientes, mas também buscam legitimidade institucional (DiMaggio \& Powell, 1983).

A legitimidade faz parte do conceito central do institucionalismo organizacional (Scott \& Meyer, 1991, Suchman, 1995, Scott, 1995/2014, Ruef \& Scott, 1998, Machado-da-Silva, Fonseca, \& Crubellate, 2005, Deephouse \& Suchman, 2008). A importância da legitimidade deriva da premissa de que as organizações, enquanto parte do sistema social (Parsons, 1956), necessitam mais do que recursos técnicos e informação do ambiente, elas necessitam de aceitação e de credibilidade (Scott et al., 2000).

A governanca corporativa pode funcionar como um instrumento para obtenção de legitimidade, na medida em que engloba a transparência nos procedimentos contábeis, mitiga a assimetria de informações e reconhece os direitos de todos os stakeholders. Além disso, a governança corporativa pode ser indutora de ações em prol da sustentabilidade, para divulgação em seus relatórios, uma vez que as práticas de governança, além da preocupação com o registro de transações econômicas, valorizam evidenciações que envolvem a dimensão ambiental (Kolk, 2008).

A essência da sustentabilidade foi capturada nos trabalhos de Elkington (2012, 1999), que sugere que os negócios necessitam de uma medida de sucesso que considere não somente o bottom line da performance financeira, mais frequentemente expressa em termos de lucros, retorno sobre o investimento, ou valor para os acionistas, mas também pelos seus amplos impactos na economia, no ambiente e na sociedade em que opera.

Nesse sentido, o trabalho procura fazer uma leitura da convergência entre a governança corporativa e a sustentabilidade, dois temas que vêm movimentando o mercado e a sociedade. Ações para a solução ou minimização dos danos causados à natureza por conta da utilização dos recursos naturais carecem do esforço de todos. Nesse contexto, estão as empresas que, por pressão da sociedade ou por interesse genuíno de preservação, começam a direcionar esforços no sentido de buscar soluções para a problemática ambiental (Capra, 2005), e a governança corporativa pode ser um instrumento importante na relação com os stakeholders de modo geral.

A questão que motiva a realização desta pesquisa é: quais as convergências teóricas das temáticas governança corporativa e sustentabilidade, pela perspectiva da legitimidade? Este trabalho, de cunho teórico, tem como principal objetivo analisar, a partir da evolução histórica de suas abordagens, a relação entre os temas governança corporativa e sustentabilidade, tendo como base a legitimidade na abordagem da teoria institucional.

Como estratégia para a revisão de literatura, buscou-se amparo teórico no estado da arte da abordagem sobre legitimação pela ótica da teoria institucional, governança corporativa e sustentabilidade. Para tanto, utilizou-se o acervo de obras da HEC - Ecole de Gestion de 1'Université de Montréal e as bases de artigos científicos da Scopus e Science Direct. Selecionou-se os artigos seminais sobre as temáticas e, em seguida, verificou-se os artigos que os usaram como referência. A partir daí, optou-se pelos artigos que trouxeram novas contribuições considerando a convergência exposta na Figura 1, abaixo:

Teoria institucional e a legitimidade
A teoria institucional trabalha com o conceito de construção social, na medida em que considera os processos pelos quais as estruturas sociais, incluindo esquemas, regras, normas e rotinas, se estabelecem como diretrizes de autoridade para o comportamento. Além disso, investiga como esses elementos são criados, difundidos e adotados ao longo do espaço e do tempo pelas organizações para gerar aceitabilidade e credibilidade em seus ambientes (Berger \& Luckman, 1974, Scott, 2013).

A formulação weberiana oferece a visão central de que a legitimação ocorre por meio de uma construção coletiva da realidade em que os elementos de uma ordem social são vistos 


\begin{tabular}{|l|l|}
\hline & $\begin{array}{l}\text { como estando em consonância com normas, valores e crenças que as pessoas presumem } \\
\text { ser amplamente compartilhados (Weber, 1978, Johnson, Dowd \& Ridgeway, 2006). } \\
\text { Consequentemente, a legitimidade é indicada pela observância de: (a) um conjunto de } \\
\text { obrigações sociais, ou como (b) modelos desejáveis de ação (Drori \& Honig, 2013). }\end{array}$ \\
\hline $\begin{array}{l}\text { Governança } \\
\text { Corporativa }\end{array}$ & $\begin{array}{l}\text { A adoção dos preceitos da governança corporativa vem sendo amplamente reconhecida } \\
\text { como um fator essencial para o acesso e aceitação das empresas no mercado de capitais. } \\
\text { Além disso, a governança corporativa também funciona como catalisadora para ações em } \\
\text { prol da sustentabilidade, na medida em que aborda a importância da criação de valor } \\
\text { sustentável e do equilíbrio entre as questões econômica, social e ambiental na tomada de } \\
\text { decisões (Aras \& Crowter, 2008). }\end{array}$ \\
\hline Sustentabilidade & $\begin{array}{l}\text { Na esteira das mudancas organizacionais em prol da busca por legitimidade, o ambiente } \\
\text { social da empresa foi alterado em direção a uma atribuição de maior responsabilidade para } \\
\text { o uso da influência da organização. Os estudos sobre sustentabilidade passaram a abordar } \\
\text { a importância da transparência e da consideração, de forma sistêmica, das dimensões } \\
\text { econômica, social e ambiental nas tomadas de decisões corporativas (Elkington, 2006). }\end{array}$ \\
\hline
\end{tabular}

Figura 1 - Convergências teóricas entre a teoria institucional e a abordagem da legitimidade, a governança corporativa e a sustentabilidade.

Fonte: Elaborado pelos autores

Com relação aos crítérios para busca do referencial teórico, considerou-se que as pesquisas sobre legitimidade têm apresentado um viés mais explanatório na teoria institucional, com autores procurando solidificar um conceito fragmentado entre várias e distintas literaturas das ciências sociais (Deephouse \& Suchman, 2008). Por conta disso, o enfoque na abordagem da temática da legitimidade foi em trabalhos que objetivaram a solidificação da teoria por meio de conceituações e proposições teóricas e não pesquisas empíricas realizadas para comprovar a teoria. No tocante à governança corporativa, os materiais foram pesquisados tendo como filtro as abordagens que enfatizaram a transparência e a mitigação da assimetria de informações, preferencialmente vinculando esta característica com a sustentabilidade (Kolk, 2008, Grun, 2003). Na abordagem sobre sustentabilidade, a pesquisa envolveu trabalhos norteados pelo conceito do triple botton line que, ao longo do tempo, foi sendo modificado para a adoção sistêmica das dimensões econômica, social e ambiental (Elkington, 2012, 1999).

Por se tratar de trabalho de cunho teórico, procurou-se valorizar as obras de primeira mão, que Eco (2009) define como sendo uma edição original ou uma edição crítica da obra em apreço. Inobstante, ao mesmo tempo em que foram utilizados trabalhos seminais, também foram abordadas produções recentes, considerando que um trabalho teórico se torna adequado quando o seu referencial é atual e de qualidade e quando o autor privilegia as fontes primárias (Alves-Mazzoti \& Gewandsznajder, 2000). Desta maneira, valendo-se de materiais disponíveis em livros, artigos e redes eletrônicas, atendeu-se a aspectos que Eco (2009) descreve como sendo esperados no processo de construção da pesquisa neste tipo de técnica: realização de um histórico das temáticas; atualização sobre o tema escolhido; formulação de questão de pesquisa e abordagem de contradições sobre o tema.

Assim, o artigo inicialmente analisa, sob a perspectiva da teoria institucional, a abordagem sobre legitimidade como fator de explicação e justificação que antecede a institucionalização. A seguir, é explorada a governança corporativa e, por fim, a sustentabilidade.

\section{FUNDAMENTAÇÃO TEÓRICA}

A revisão de literatura inicialmente analisa os aspectos da legitimidade, sob a perspectiva da teoria institucional. A seguir, é explorada a temática da governança corporativa e sua inerente busca pele assimetria de informações e transparência. Prosseguindo, é abordada a sustentabilidade através das dimensões econômica, social e ambiental e suas interconexões. 


\subsection{Teoria institucional e a legitimidade}

As raízes da teoria institucional surgiram entre o final do século XIX e o início do século XX, principalmente com os trabalhos de Marx, Weber, Cooley, Mead e Commons. Porém, a teoria institucional perdeu muito espaço por conta dos ataques da teoria neoclássica, no campo da economia; do behaviorismo, no campo da ciência política; da sociologia e do positivismo. Inobstante, experimentou um renascimento notável na segunda metade do século XX e ficou conhecida como moderna institucionalidade (Scott, 1987).

As bases conceituais da moderna institucionalidade nas organizações foram estabelecidas nas obras de Berger e Luckmann (1974), Williamson (1975), Meyer e Rowan (1977), Hannan e Freeman (1977), Zucker (1977); Giddens (1979); DiMaggio e Powell (1983), Tolbert e Zucker (1983) e Scott (1987). A teoria institucional trabalha com o conceito de construção social, na medida em que considera os processos pelos quais as estruturas sociais, incluindo esquemas, regras, normas e rotinas, se estabelecem como diretrizes de autoridade para o comportamento social. Além disso, investiga como esses elementos são criados, difundidos e adotados ao longo do espaço e do tempo (Scott, 2013). DiMaggio e Powell (1983) destacam que forças de pressão comuns às organizações as levam a buscar uma conformidade com o mundo exterior. Essas colocações estão alinhadas com o entendimento de que as organizações não competem apenas por recursos e clientes, adicionalmente buscam uma legitimidade institucional (Dowling \& Pfeffer, 1975). Nesse sentido, a legitimidade de estruturas, ações e práticas organizacionais ganham importância, no mínimo equivalente, às ligadas à eficiência técnica (Meyer \& Rowan, 1977; DiMaggio \& Powell, 1983).

A origem da premissa que aborda a importância da legitimidade no institucionalismo organizacional é, predominantemente, creditada a Weber (Deephouse \& Suchman, 2008). Para Weber (1978), as práticas sociais balizadas por máximas ou regras aceitas como obrigatórias, que, por sua vez, são tidas como socialmente válidas pelos agentes. Assim, se elas se referem à aceitação das formas de conduta de qualquer ator social, elas podem também envolver as organizações, já que essas são tidas como agentes que atuam em uma realidade social e que pode levá-las a buscar conformidade (Scott, 2013).

Weber (1978) argumentou que a ordem social é legítima "[...]apenas se a ação é de aproximadamente ou, em média, orientada para certas 'máximas' determinados ou regras" (p.31). O autor observa que, embora as pessoas individualmente nem sempre têm as mesmas normas, valores e crenças, o seu comportamento, no entanto, torna-se orientado para uma ordem que está de acordo com as regras que presumem serem aceitas pela maioria dos outros. Se os indivíduos percebem que os outros suportam esta ordem social, a ordem parece ser um fato social válido e objetivo. Consequentemente, os indivíduos agem de acordo com essa ordem, mesmo se eles não concordam em particular com ela.

Assim, a formulação weberiana oferece a visão central que a legitimação ocorre por meio de uma construção coletiva da realidade social em que os elementos de uma ordem social são vistos como consonantes com as normas, valores e crenças que as pessoas presumem são amplamente compartilhados (Johnson, Dowd, \& Ridgeway, 2006). Consequentemente, a legitimidade é indicada pelo cumprimento dos atores com uma ordem social como: (a) um conjunto de obrigações sociais, ou como (b) um modelo desejável de ação (Walker, 2004),

O primeiro autor a relacionar a ideia de legitimidade weberiana no contexto organizacional foi Parsons (1956), que definiu as organizações como um sistema orientado para a realização de metas específicas, mas que, necessariamente, contribuam com o sistema social mais amplo. $\mathrm{O}$ autor discorre que a partir do momento que as organizações usam recursos do ambiente, a sociedade constantemente avalia se suas ações são apropriadas e se seus produtos ou resultados são socialmente úteis. Assim, as organizações devem ser entendidas como estando imersas no ambiente social e considerando sua congruência com o sistema de valores, crenças, leis e normas (Salancik \& Pfeffer, 1978, Rossoni, 2012). 
Conforme Berger e Luckman (1974), a formação do hábito acarreta importante ganho psicológico na medida em que estreita as opções e gera estabilidade. A parte mais importante da formação do hábito é coextensiva com a institucionalização da atividade humana. A institucionalização ocorre sempre que há uma tipificação recíproca de ações habituais por tipos de atores, as quais são partilhadas pelos atores na organização. Para que a institucionalização possa ser sedimentada é necessária a legitimação, que é o processo de explicação e justificação do mundo institucionalizado (Berger \& Luckmann (1974).

A legitimidade, dentro do escopo do novo institucionalismo, surgiu concomitantemente ao próprio nascimento desta abordagem. Meyer e Rowan (1977) a tomam como um de seus elementos centrais, juntamente com os recursos, para a explicação da sobrevivência das organizações. Segundo Meyer e Rowan (1977, p. 352): “[...]aquelas organizações que incorporam elementos racionalizados socialmente legitimados em suas estruturas formais maximizam sua legitimidade e aumentam seus recursos e capacidades de sobrevivência”.

O grande desenvolvimento da questão da legitimidade organizacional ocorreu em meados da década de 1990, com os trabalhos de Scott (1995/2013) e Suchman (1995). Suchman (1995, p. 574) observou a natureza coletiva da legitimidade considerando que um determinado padrão de comportamento possui legitimidade é porque que um grupo de observadores, como um todo, aceita ou suporta o que aqueles observadores consideram ser o padrão de comportamento esperado. Scott (2013) observa que as organizações precisam de mais do que recursos materiais e técnicos para permanecerem viáveis, também precisam de apoio cultural. Nessa mesma linha, Suchman (1995) situou a fonte de legitimidade além dos limites de uma organização individual, considerando a inserção das crenças organizacionais na sociedade. Assim, os dois autores convergem na interpretação de que uma organização se legitima por meio da autorização ou aprovação de determinados atores no ambiente circundante.

Scott (2013) discorre sobre o processo de legitimidade, considerados os aspectos: regulamentares, normativos e cultural-cognitivos. A legitimidade regulamentar flui de atores que têm algum tipo de soberania sobre as organizações, tais como agências reguladoras associadas com os governos e que, assim, definem a faixa do que é legal ou processual aceitável, via exigências e sanções. Legitimidade normativa decorre de atores que definem o que é moralmente desejável (ao invés de legalmente obrigatório), com profissões e suas associações fornecendo um exemplo notável dos que estipulam as normas e os valores. Finalmente, legitimidade cultural-cognitiva flui da prevalência de atores organizacionais comparáveis, proporcionando assim modelos de estruturas e ações organizacionais.

Legitimidade também é importante para a estabilidade da ordem de status informais (Ridgeway \& Berger, 1986). Muitos desses processos, tais como a formação de normas, desvios e controle social, e os sentimentos e emoções, também podem dar origem a uma estrutura emergente. A estabilidade das estruturas emergentes é um dos problemas a serem resolvidos por qualquer teoria dos processos de legitimação, pois a legitimidade é exatamente um fator de estabilidade. Por conta disso, a legitimidade é um fenômeno que pode ser visto como auxiliar no sentido da busca de aceitação ou redução de resistência, e que também pode ser visto com uma forma de justificação (Zelditch, 2001).

A crença de que algo é amplamente aceito faz com que a justificação seja aceitável, mesmo que, pessoalmente, alguém não acredite na justificação. É mais provável a aceitação de algo como apropriado quando se pressupõe que a maioria (entendimento coletivo) acredita que é apropriado. Desta forma, obtém-se a validade (Massey, Freeman \& Zelditch, 1997) e é a validade que determina a probabilidade de aceitação (Johnson, Dowd \& Ridgeway, 2006).

A finalidade de uma justificação é fazer com que determinada conduta seja aceitável para outros. O que importa é o que os outros pensam. De alguma forma, uma justificação sempre liga o não aceito ou inaceitável com normas aceitas, valores, crenças, práticas ou procedimentos. O inaceitável se torna aceitável, na medida em que se estabeleçam normas, valores, crenças, práticas 
ou procedimentos para que os apelos de justificação sejam aceitos, e também que pareça estar fundamentado em credibilidade (Zelditch \& Floyd, 1998).

Nesse contexto, a legitimação é, em grande parte, um processo implícito em que as crenças culturais amplamente compartilhadas criam fortes expectativas para o que é provável de ocorrer na situação local. Fortes expectativas de que será de determinada maneira, impulsionam indicações comportamentais de aceitação e o aparecimento de aceitação consensual dessas manifestações comportamentais legitima a ordem (Johnson, Dowd \& Ridgeway, 2006).

\subsection{Governança corporativa}

As práticas de governança corporativa vinculadas às temáticas da responsabilidade social corporativa e da sustentabilidade tem sido tema de múltiplos estudos, e tem como principal origem o trabalho de Bowen (1957), que abordou uma visão de responsabilidade social alinhada com as políticas da empresa, em contraponto com a abordagem filantrópica que o tema carregava nos primórdios. Na visão de Bowen (1957), a responsabilidade social corporativa deixaria de ser apenas um conjunto de ações paternalistas de filantropia para estar inserida nas políticas das organizações (Milani, Righi, Ceretta, \& Dias, 2012).

O interesse pela adoção de políticas de governança corporativa ganhou corpo após grandes escândalos corporativos, como os da Enrom, AGF, e a Crise do Subprime, na primeira década do século XXI. Os investidores passaram a exigir a implementacao de princípios de governança corporativa, a fim de alcançar melhores retornos sobre seus investimentos e reduzir os custos de agência (Jensen \& Meckling, 1976) e, na maioria das vezes, os investidores estão dispostos a pagar mais para que as empresas que apresentem padrões de governança (Beiner, Drobetz, Schmid, \& Zimmermann, 2006).

As tentativas recentes para fortalecer a governança corporativa e a prestação de contas, após esses escândalos, têm focado os mecanismos internos referentes a conselhos, gestores, auditores, controle e aspectos de risco, em especial para aumentar a transparência para os acionistas e influenciar o comportamento das empresas em toda a gama de assuntos de negócios, considerando os aspectos éticos inerentes à remuneração, ao comportamento gerencial e de funcionários (Kolk, 2008).

Como reflexo, verifica-se nos últimos anos um rápido aumento das pressões para o aumento da transparência, o que gera requisitos de prestação de contas no contexto da governança corporativa, os quais se expandem para aspectos éticos relacionados com o pessoal, e relatórios de sustentabilidade, considerando os aspectos financeiros, sociais e ambientais (lucro, pessoas, planeta) (Elkington, 2006, Kolk, 2005). Com isso, forte atenção tem sido dada aos relatórios de sustentabilidade e de auditoria (Owen, Swift, Humphrey, \& Bowerman, 2000).

O Instituto Brasileiro de Governança Corporativa (IBGC, 2015) conceitua governança corporativa como o sistema pelo qual as sociedades são dirigidas e monitoradas, envolvendo os relacionamentos entre acionistas, conselhos de administração, diretoria, auditoria independente e conselho fiscal. A preocupação da governança corporativa é criar um conjunto eficiente de mecanismos, tanto de incentivos quanto de monitoramento, a fim de assegurar que o comportamento dos administradores esteja sempre alinhado com o melhor interesse da empresa.

A boa governanca é importante em todas as esferas da sociedade, quer seja no ambiente corporativo ou da sociedade em geral ou o ambiente político. A governança corporativa pode ser considerada como um ambiente de confiança, ética, valores morais e de confiança - como um esforço sinérgico de todos os componentes da sociedade - isto é, os stakeholders, incluindo o governo, os profissionais, os prestadores de serviços e o setor corporativo e tudo isso pode ser reforcado com um novo paradigma de governança corporativa que está em sintonia com a mudança dos tempos e que considera a demanda por uma maior responsabilização das empresas (Bushman \& Smith, 2001). 
Dois aspectos marcantes da governanca corporativa, então, são a redução da assimetria das informações, que vai ao encontro de uma preocupação levantada pela teoria da agência (Jensen \& Meckling, 1976), e a geração de legitimidade. Com a divulgação de informações, a organização pode mitigar as vantagens e desvantagens de acesso privilegiado a informações (Lambert, Leuz, \& Verrecchia, 2007) e também propiciar ganhos em termos de legitimidade organizacional com o uso de ações simbólicas, que fazem parte da imagem pública da organização e que é pautada em valores compartilhados pela população em geral (Neu, Warsame, \& Pedwell, 1998).

A perspectiva dominante que consta nos artigos sobre governança corporativa compreende: proteger os direitos dos acionistas; assegurar o tratamento equitativo de todos os acionistas, inclusive minoritários e estrangeiros; reconhecer os direitos de todos os stakeholders, certificaremse de que a divulgação deve ser feita englobando todas as questões relevantes relacionadas à empresa; garantir a orientação estratégica da empresa, o controle eficaz da gestão pelo conselho e a prestação de contas da diretoria para a empresa e acionistas (Stead \& Stead, 2013, Cartwrigh \& Craig, 2006). Cartwrigh e Craig (2006) ainda acrescentaram que a Terra - o ambiente natural deveria ser considerada como stakeholder.

Alguns ativistas e ambientalistas sugerem, inclusive, uma regulamentação mais rígida, argumentando que a ação voluntária é improvável ou insuficiente, outros sugerem educar e organizar consumidores para forçarem as empresas a se tornarem mais sustentáveis. Tanto a legislação como a educação são necessárias, porém elas podem não ser capazes de resolver o problema rapidamente ou completamente. Diante disso, o papel das empresas e a forma como os seus executivos se posicionam passa a ser fundamental para o surgimento de práticas voltadas à sustentabilidade (Nidumolu, Prahalad, \& Rangaswami, 2009).

Desta maneira, as organizações, com a divulgação de suas práticas e políticas, buscam estabelecer congruência entre os valores sociais associados às suas atividades e as normas de comportamentos aceitáveis no sistema social maior do qual fazem parte. Nessa esteira, a divulgação das ações em prol da sustentabilidade pode representar uma estratégia para responder às expectativas da sociedade. Nesse sentido, a governança corporativa surgiu como possível indutora de ações em prol da sustentabilidade.

Michelon e Parbonetti (2012) discorrem que a boa governança corporativa e a divulgação das ações em prol da sustentabilidade podem ser percebidas como mecanismos complementares de legitimidade e que as empresas podem utilizá-los para a construção de diálogos com os stakeholderes. A legitimidade organizacional, além de garantir o fluxo de capital, trabalho e clientes necessários para a viabilidade da empresa (Pfeffer \& Salancik 2003, Neu et al.,1998), também é capaz de reduzir possíveis boicotes de produtos e ações de ruptura causados por abalos na reputação (Elsbach, 1994).

A governança corporativa das companhias tem sido objeto de estudos nacionais e internacionais, sendo amplamente reconhecida como um fator essencial para o acesso das empresas no mercado de capitais, visto que tem a transparência como fator determinante nesse processo. Isso acontece, provavelmente, como uma das consequências de que a sociedade passou a demandar das empresas informações sobre a sustentabilidade, induzindo à incorporação de aspectos econômicos, sociais e ambientais nos relatórios do meio empresarial (Leo \& Robles, 2006).

Nesse contexto da governança corporativa, a contabilidade, além do registro de transações econômicas, passa a apresentar eventos ambientais, assumindo o papel de divulgação das ações de gestão ambiental, tendo em vista prevenir e corrigir danos, bem como salvaguardar os patrimônios empresarial e nacional. Assim, a boa governança corporativa pode ser o instrumento para deflagração de um ciclo virtuoso, em que a transparência nos procedimentos contábeis e administrativos das empresas de capital aberto e o respeito aos direitos dos acionistas minoritários são as bases de sustentação da nova institucionalidade (Grun, 2003). 


\subsection{Sustentabilidade}

Em muitos campos da sociedade, a sustentabilidade tornou-se foco de debates. Parece crescer um entendimento coletivo de que as organizações humanas precisam passar por uma mudança fundamental para se tornar sustentáveis do ponto de vista ecológico, na medida em que constituem a força principal de destruição do ambiente planetário (Goodland, 1995). A chamada Grande Lei da Confederação Iraquiana da Paz, de 1142, traz elementos consagrados do pensamento e da responsabilidade de longo prazo, intra e intergeracional de equivalência patrimonial, o que é central para a noção de sustentabilidade. Adiantando-se oito séculos, em 1960 começam a aparecer argumentos para a proteção da biodiversidade e no início da década de 1970 publicações sobre os limites alarmantes de crescimento, que previu um planeta superpovoado, além de abordagens sobre a agricultura sustentável. Comecava, então, a surgir uma ideia moderna da sustentabilidade: preservar a vida na Terra para manter o futuro da humanidade.

Essa visão histórica é, em geral, menosprezada nos textos de autores norte-americanos e europeus, que colocam a década de 1970 como marco fundamental do movimento pelo desenvolvimento sustentável (Barbieri, Vasconcelos, \& Andreassi, 2010). Foi a Conferência das Nações Unidas sobre o Ambiente Humano, de 1972, ocorrida em Estocolmo, que colocou a dimensão do meio ambiente na agenda internacional, abordando, pela primeira vez, as dependências entre o desenvolvimento e o meio ambiente. O crescimento econômico foi reconhecido como necessário para o bem-estar da sociedade presente, mas não deveria ser obtido por meio da incorporação predatória do capital da natureza (Sachs, 2009). Essa abordagem de Sachs (2009) é bem aderente com uma perspectiva que defende um pacto intra e intergerações em relação à preservação do meio ambiente e geração de uma sociedade mais justa tem a ver com o desenvolvimento sustentável.

O marco do desenvolvimento sustentável ocorreu em 1987, com o relatório da Comissão Mundial sobre Meio Ambiente e Desenvolvimento (Cmmad), conhecida como Comissão de Brundtland. Por essa perspectiva, as decisões organizacionais têm que levar em conta a necessidade de reavaliação contínua dos limites finitos do espaço que o homem ocupa e a sua capacidade de suporte para que as futuras gerações tenham acesso aos recursos provedores de uma vida satisfatória (Holdren \& Ehrlich, 1971).

A partir da segunda metade de década de 1990, o entendimento sobre sustentabilidade e responsabilidade social corporativa ganhou ainda mais corpo no sentido de valorizar a construção de relacionamentos de longo prazo com os stakeholders: clientes, fornecedores, empregados, acionistas e comunidade em geral, e reconhecer o impacto das atividades produtivas na degradação dos recursos comuns do meio ambiente (Polonski \& Rosenberger, 2001).

Conforme Capra (2005), o mercado impõe a mudança, a adaptabilidade e a criatividade contínuas. Ao mesmo tempo, as organizações são comunidades de pessoas que interagem umas com as outras para construir relacionamentos, ajudar-se mutuamente e tornar significativas as suas atividades cotidianas em um plano pessoal, mas também são instituições sociais criadas com objetivos específicos de gerar ganhos para os acionistas, administrar a distribuição do poder e transmitir conhecimento.

Apesar da necessidade da busca por resultados no campo econômico, Sachs (2009) defende uma abordagem holística e interdisciplinar, na qual cientistas naturais e sociais trabalhem juntos em favor do alcance de caminhos sábios para o uso e o aproveitamento dos recursos da natureza, respeitando a sua diversidade. $\mathrm{O}$ uso produtivo não necessariamente precisa prejudicar o meio ambiente ou destruir a diversidade se houver a consciência de que todas as atividades econômicas estão solidamente fincadas no ambiente natural.

Nesse contexto, o paradigma de desenvolvimento amparado na produção de bens e serviços e idealizado pelo prisma capitalista precisa ser revisto. $\mathrm{O}$ meio ambiente e seus recursos naturais não podem ser vistos apenas como insumo para o processo produtivo. Isso porque as preocupações 
de todos os stakeholders de uma organização devem ser levadas em consideração (Johnson \& Greening, 1999, Knox \& Maklan, 2004).

Moneva, Rivera-Lirio e Muñoz-Torres (2007) sugerem que culturas corporativas que incorporam comprometimento e valores sociais e éticos podem atrair e manter os melhores funcionários, aumentar a produtividade e evitar infrações legais, reduzindo os custos e gerando os melhores resultados em termos financeiros, o que mantém certa aderência com os preceitos da World Business Council for Sustainable Development (WBCSD), que defende que o comprometimento corporativo é fundamental para contribuir com o desenvolvimento econômico sustentável, empregados e seus familiares, comunidade local e ampla sociedade no sentido de aperfeiçoamento de sua qualidade de vida.

Diante disso, o papel das empresas, e a forma como os seus executivos se posicionam passa a ser fundamental para o surgimento de práticas voltadas ao desenvolvimento sustentável (Nidumolu et al., 2009). Elkington (2012) afirma que o desenvolvimento sustentável deve atender, de forma sistêmica, três dimensões essenciais: econômica, social e ambiental. O pilar ambiental defende a conservação e o manejo dos recursos naturais; o pilar econômico refere-se às consequências financeiras das ações da empresa para os stakeholders; e o pilar social alude à participação na manutenção e no aperfeiçoamento do equilíbrio do sistema, no que tange a direitos e responsabilidades.

Nesse contexto, parece crescer uma sensibilização coletiva no sentido de que as organizações precisam passar por uma mudança fundamental. $\mathrm{O}$ atual modelo econômico foi alicerçado na visão da inesgotabilidade dos recursos ecológicos, em especial os energéticos. Uma nova forma de gerir os recursos disponíveis na natureza se faz premente, na medida em que formas arcaicas de gestão não atendem mais o intuito de desenvolvimento sustentável (Dreher, Casagrande \& Gomes, 2012).

Inobstante, no campo organizacional, nem sempre são consideradas todas as dimensões da sustentabilidade, e, tradicionalmente, a ênfase é na dimensão econômica, em detrimento das demais. Muitos problemas socioambientais foram causados porque decisões simples e fragmentadas visavam atender apenas à dimensão econômica, dentro do conceito de homem econômico, defendido pelos pensadores clássicos da Administração, ou pelo conceito da racionalidade limitada estudada por Simon (1979).

Depreende-se, então, que o propósito de um processo de desenvolvimento sustentável é atingir a sustentabilidade em suas diferentes dimensões, e a qualidade do processo é cada vez mais cobrada pela sociedade. Alguns sintomas desta cobrança podem ser identificados com os relatórios de sustentabilidade, que passaram a ser utilizados para a prestação de contas das organizações, e também a criação do Índice de Sustentabilidade Empresarial (ISE), pela Bolsa de Valores de São Paulo, com intuito de premiar as empresas que procuram aliar desenvolvimento com ecoeficiência e responsabilidade social (Nunes, Teixeira \& Galdi, 2010), o que acaba por criar um elo muito forte entre governança corporativa e sustentabilidade.

Em suma, o período que se vive, de constantes debates sobre a importância da sustentabilidade, cria um terreno fértil não só para a ampliação e o aprofundamento das pesquisas no campo acadêmico, mas principalmente para que a lógica do desenvolvimento sustentável seja difundida nas práticas organizacionais. É necessário, então, compreender que os esforços empreendidos no processo do desenvolvimento sustentável podem conduzir para a sustentabilidade, tanto como produto final quanto na geração de qualidade no processo (Dreher \& Casagrande, 2012).

\section{CONSIDERAÇÕES FINAIS}

O processo de institucionalização, no âmbito das empresas, gera mitos que fazem com que as organizações respondam adotando modelos tidos como melhores práticas (Meyer \& Rowan, 1977), podendo gerar certa conformidade em que predomina um conjunto de regras e máximas que controlam a conduta humana e determinam a ordem social (Scott \& Rowan, 1981).

Revista de Gestão Social e Ambiental - RGSA, São Paulo, v. 9, n. 2, p. 88-101, mai./ago., 2015. 
A temática da legitimação ocupa papel de protagonismo na institucionalização, e prevalecem abordagens que enfatizam que um comportamento possui legitimidade devido a um grupo de observadores, como um todo, aceitá-lo ou suportá-lo, passando a gerar um padrão esperado (Scott, 2013, Suchman, 1995). Nesse sentido, a legitimação envolve a construção de uma realidade social, a partir do estabelecimento de normas, rotinas, crenças e procedimentos objetivados no meio corporativo, servindo como uma explicação e justificação que antecede a institucionalização (Zelditch \& Floyd, 1998, Zelditch, 2001). Na medida em que a legitimação é uma construção coletiva da realidade social (Berger \& Luckmann, 1974), é possível inferir que a governança corporativa se enquadra como um dos procedimentos utilizados pela organização que impacta no processo de legitimação de suas práticas, em especial da sustentabilidade, figurando, inclusive, como uma das categorias presentes no Global Reporting Initiative (GRI) para divulgação das ações voltadas à sustentabilidade, consideradas as dimensões econômica, social e ambiental.

O debate sobre a importância da governança corporativa ganhou bastante espaço após os escândalos de empresas como AGF, Enrom, Arthur Andersen, sem contar a crise subprime, que passou uma imagem de falta de comprometimento com princípios de gestão dos recursos de terceiros (Kolk, 2008). Ficou evidenciada a falta de comprometimento dos administradores e, como consequência, percebe-se um aumento na demanda por maior transparência de parte das empresas e regulamentação mais forte, no sentido de reforcar o comportamento ético por parte de governos, empresas e indivíduos (Elkington, 2012).

$\mathrm{Na}$ esteira dessas preocupações, a tendência do desenvolvimento sustentável parece ser um dos mais importantes movimentos sociais deste início de século, pela rapidez que vem sendo aceito pelo empresariado, ao menos no nível do discurso, e pelas incontáveis iniciativas voluntárias em direção a uma nova forma de perceber os impactos das decisões corporativas não apenas sob a ótica utilitarista, que tem um foco mais alinhado ao aspecto econômico, mas também colocando na equação os reflexos sociais e ambientais (Capra, 2005, Sachs, 2009).

Questões ainda mais amplas, como a ética nos negócios, os direitos humanos, o suborno e a corrupção, bem como as mudanças climáticas, passam a compor as grandes questões do nosso tempo. Como resultado, uma proporção crescente do trabalho sobre sustentabilidade viu a fusão de governança corporativa com as preocupações mais amplas da sociedade. Nesse sentido, o conceito de desenvolvimento sustentável apresenta pontos básicos que devem considerar, de maneira harmônica, o crescimento econômico, uma maior percepção com os resultados sociais decorrentes e o equilíbrio ecológico na utilização dos recursos naturais (Elkington, 2012).

Em muitos campos da sociedade e do mercado, a sustentabilidade tornou-se um foco de debates que transcende o entendimento dos princípios que vislumbram esta proposta e, neste meio, há muitos mitos e discursos utópicos. O atual modelo econômico foi assentado na visão antropocêntrica e na inesgotabilidade dos recursos ecológicos, em especial os energéticos, por isso a mudança deste paradigma exige um tempo de compreensão e reação (Dreher et al., 2012). Há a necessidade de um pacto intra e intergerações, o qual pressupõe que determinados recursos, chamados de não-renováveis (matérias-primas de natureza extrativa, tais como, ferro ou petróleo, carvão), se utilizados de forma desmedida no presente não estarão disponíveis para utilização no futuro (Sachs, 2009).

Há de se reconhecer que a temática sustentabilidade ainda é uma questão controversa e existem muitas definições sobre o que se quer dizer com o termo (Barbieri et al., 2010). No cerne deste contrato social, está a preocupação com o futuro, que se manifesta por meio da sustentabilidade e que se tornou onipresente tanto no discurso da globalização quanto na análise do desempenho corporativo. Uma materialização da preocupação com a sustentabilidade se dá por meio da adoção das práticas da governança corporativa, com sua transparência e busca por assimetria de informações, inclusive para os acionistas minoritários (Grun, 2003, Elkington, 2006, Kolk, 2008). 
A transparência propiciada pela governança corporativa pode mitigar um comportamento danoso ao desenvolvimento sustentável. Muitas organizações demonstram um foco mais utilitarista em suas ações, com uma ênfase maior na dimensão econômica em detrimento das demais. $\mathrm{Na}$ medida em que as organizações precisam lutar não apenas por recursos, mas também por legitimidade (Dowling \& Pfeffer, 1975), a preocupação com a forma como os stakeholders vão perceber a empresa tende a fazer da governança corporativa um catalisador do processo de sustentabilidade que considera, conjuntamente, as três dimensões: econômica, social e ambiental (Elkington, 2012).

Os resultados da pesquisa demonstram que a governança corporativa recebe alta prioridade na agenda dos formuladores de políticas organizacionais, investidores e acadêmicos, indicando que a ligação entre essa temática, com a busca por legitimidade e a sustentabilidade, mostra-se um tema profícuo para a produção de pesquisas. Como sugestão, um campo interessante para aprofundamento nos estudos sobre a inter-relação das temáticas governança corporativa e legitimidade pode ser a análise de estratégias organizacionais para gestão dos conflitos ocasionados por eventuais faltas de alinhamento entre a legitimidade interna e as demandas de legitimidade do ambiente externo, conforme abordado nos trabalhos de Johnson, Dowd \& Ridgeway (2006) e Drori e Honig (2013).

\section{REFERÊNCIAS}

Alves-Mazzotti, A. J., \& Gewandsznaider, F. (2000) O método nas ciências naturais e sociais: pesquisa quantitativa e qualitativa. São Paulo: Pioneira.

Aras, G. \& Crowther, D. (2008) Governance and sustainability: an investigation into the relationship between corporate governance and corporate sustainability. Management Decision. 46 (3), 433-448.

Barbieri, J.C., Vasconcelos, I. F.G de. Andreassi, T., \& Vasconcelos, F. C. de (2010) Inovação e Sustentabilidade: novos modelos e proposições. RAE - Revista de Administração de Empresas, 50 (2), 146-154.

Beiner, S., Drobetz, W., Schmid, M. M., \& Zimmermann, H. (2006) An integrated framework of corporate governance and firm valuation. European Financial Management, 2 (2), 249-283.

Berger, P. L., \& Luckmann, T. A. (1974) A construção social da realidade: tratado de sociologia do conhecimento. Petrópolis: Vozes.

Bowen, H. R. (1957) Responsabilidades sociais do homem de negócios. Rio de Janeiro: Civilização Brasileira.

Bushman, R. M., \& Smith. A. J. (2001) Financial accounting information and corporate governance. Journal of accounting and Economics, 32 (1), 237-333.

Cartwrigh, W., \& Craig, J. L. (2006) Sustainability: aligning corporate governance, strategy and operations with the planet. Business Process Management Journal, 12 (6), 741-750.

Capra, F.(2005) As conexões ocultas: ciência para uma vida sustentável. São Paulo: Cultrix.

Deephouse, D. L., \& Suchman, M. (2008) Legitimacy in organizational institutionalism. In: Greenwood, R., Oliver, C., Sahlin, K., \& Suddaby, R. (Eds). The Sage Handbook of Organizational Institutionalism. London: Sage, 49-77.

Dimaggio, P. J., \& Powell, W. W. (1983) The iron cage revisited: institutional isomorphism and collective rationality in organizational fields. American Sociological Review, 48 (2), 147-160. 
Dowling, J., Pfeffer, J. (1975) Organizational legitimacy: social values and organizational behavior. Pacific Sociological Review, 18 (1), 122-136.

Dreher, M. T., Casagrande, R. M., Gomes, G. (2012) Inovacão e Sustentabilidade: Desafios da Consultoria Ambiental. In: Semead Desafios da Gestão: Econômico, Social e Ambiental, 15.

Drori, I., Honig, B. (2013) A process model of internal and external legitimacy. Organizational Studies, 34 (3), 345-376.

Eco, H. (2009) Como se faz uma tese. São Paulo: Perspectiva.

Elkington, J. (1999) Triple Bottom-Line Reporting: looking for balance. Australian: CPA.

Elkington, J.B. (2006) Governance for sustainability. Corporate Governance,14(6).

Elkington, J. (2012) Sustentabilidade: canibais com garfo e faca. São Paulo: M. Books do Brasil.

Elsbach, K. D. (1994) Managing organizational legitimacy in the California cattle industry: The construction and effectiveness of verbal accounts. Administrative Science Quarterly, 39, (1), 57-88.

Giddens, A. (1979) A constituição da sociedade. São Paulo: Martins Fontes.

Goodland, R. (1995) The concept of environment sustainability. Annual Review of Ecology and Systematics, 26, 1-24.

Grun, R. (2003) Atores e ações na construção da governança corporativa brasileira. Revista Brasileira de Ciências Sociais, 18 (52).

Hannan, M. T., \& Freeman, J. (1977) The population ecology of organizations. American Journal of Sociology, 82, 929-964.

Holdren, P. J., \& Ehrlich, R. P. (1971) Global ecology: reading toward a rational strategy for man. New York: Harcout Brace Jovanovich.

IBGC - Instituto Brasileiro de Governança Corporativa. (2015) Origem da boa governança. Recuperado em 02 nov. 2015: < http://www.ibgc.org.br/inter.php?id=18166>.

Jensen, M. C., \& Meckling, W. H. (1976) The theory of firm: managerial behavior, agency costs and ownership structure. Journal of Financial Economics, 3 (4), 305-360.

Johnson, C., Dowd, T. J., \& Ridgeway, C. L. (2006) Legitimacy as a social process. Annual Review of Sociology, 32, 53-78.

Johnson, R. A., \& Greening, D. W. (1999) The effects of corporate governance and institutional ownership types on corporate social performance. Academy of Management Journal, 42 (5), 564576.

Knox, S., \& Maklan, S. (2004) Corporate social responsibility: moving beyond investment towards measuring outcomes. European Management Journal, 22 (5), 508-516.

Kolk, A. (2005) Environmental reporting by multinationals from the Triad: Convergence or divergence? Management International Review, 45 (1), 145-166.

Kolk, A. (2008) Sustainability, accountability and corporate governance: Exploring multinationals reporting practices. Business Strategy and the Environment, 17 (1), 1-15.

Lambert. R.. Leuz. C.. \& Verrecchia. R. E. (2007) Accounting information, disclosure, and the cost of capital. Journal of Accounting Research, 45 (2), 385-420. 
Leo, J. E. P. T., \& Robles, T. (2006) A contabilidade da gestão ambiental e sua dimensão para a transparência empresarial: estudo de caso de quatro empresas brasileiras com atuação global. $R A P$, Rio de Janeiro, 1077-1096.

Machado-Da-Silva, C. L., Fonseca, V. S., \& Crubellate, J. M. (2005) Unlocking the institutionalization process: insights for an institutionalizing approach. Brazilian Administration Review, .2 (1), 01-20.

Massey, K., Freeman, S., \& Zelditch, M. (1997) Status, power, and accounts. Social Psychology Quarterly, 60, 3, 238-251.

Meyer, J. W., \& Rowan, B. (1977) Institutionalized organizations: formal structure as myth and ceremony. American Journal of Sociology, 83 (2), 340-363.

Michelon, G., \& Parbonetti, A. (2012) The effect of corporate governance on sustainability disclosure. Journal of Management \& Governance, 16 (3), 477-509.

Milani, B., Righi, M. B., Ceretta, P. S., \& Dias, V. (2012) Práticas de sustentabilidade, governança corporativa e responsabilidade social afetam o risco e o retorno dos investimentos? Revista de Administração da UFSM, 5, 667-682.

Moneva, J. M., Rivera-Lirio, J. M., \& Muñoz-Torres, M. J. (2007) The corporate stakeholder commitment and social and financial performance. Industrial Management \& Data Systems, 107 (1), 84-102.

Neu, D., Warsame, H., \& Pedwell, K. (1998) Managing public impressions: environmental disclosures in annual reports. Accounting, Organizations and Society, 23 (3), 265-282.

Nidumolu, R., Prahalad, C. K., \& Rangaswami, M. R. (2009) Why sustainability is now the key driver of innovation. Harvard Business Review, 87 (9), 56-64.

Nunes, J. G., Teixeira, A. J., Nossa, V., \& Galdi, F. C. (2010) Análise das variáveis que influenciam a adesão das empresas ao índice BM\&Fbovespa de Sustentabilidade Empresarial. BASE-Revista de Administração e Contabilidade da Unisinos, 328-340.

Owen, D. L., Swift, T. A., Humphrey, C., \& Bowerman, M. (2000) The new social audits: Accountability, managerial capture or the agenda of social champions? European Accounting Review, 9 (1), 81-98.

Parsons, T. (1956) Suggestions for a sociological approach to the theory of organizations. Administrative Science Quarterly, 1, (1), 63-85.

Pfeffer, J., \& Salancik, G. R. (2003) The external control of organizations: a resource dependence perspective. Stanford University Press.

Polonski, M. J., \& Rosenberger III, P. J. (2001) Reevaluating green marketing: a strategic approach. Business Horizons, 44 (5), 21-30.

Ridgeway, C. L., \& Berger, J. (1986) Expectations, legitimation and dominance behavior in Task Groups. American Sociological Review, 51 (5), 603-617.

Rossoni, L. (2012) O que é legitimidade organizacional. Encontro de Estudos Organizacionais da Anpad, 7, Curitiba.

Ruef, M., \& Scott, W. R. (1998) A multidimensional model of organizational legitimacy: hospital survival in changing institutional environments. Administrative Science Quarterly, 43 (4) 4, 877904. 
Sachs, I. (2009) Caminhos para o desenvolvimento sustentável. Rio de Janeiro: Garamond.

Salancik, G. R., \& Pfeffer, J. (1978) A social information processing approach to job attitudes and task design. Administrative Science Quarterly, 23, (2), 224-253.

Scott, W.R. (1987) The adolescence of institutional theory. Administrative Science Quarterly, 32, 93-511.

Scott, W. R. (2013) Institutions and organizations: ideas and interests. Thousand Oaks: Sage.

Scott, W. R., \& Meyer, J. W. (1991) The organization of societal sectors: proposition and early evidence. In: Dimaggio,P., Powell, W. (Eds) The new institutionalism in organizational analysis. Chicago: The University of Chicago Press, p. 83-107.

Scott, W. R., Ruef, M., Mendel, P. J., \& Caronna, C. A. (2000) Institutional Change and Healthcare Organizations: from professional dominance to managed care. Chicago: University of Chicago Press.

Simon, H.A. (1979) Rational decision making in business organizations. American Economic Review, 69, 493-513.

Stead, J. G. \& Stead, W. E. (2013) Sustainable Strategic Management. ME Sharpe.

Suchman, M. C. (1995) Managing legitimacy: strategic and institutional approaches. Academy of Management Review, 20 (3), 571-610.

Tolbert, P. S., \& Zucker, L. (1983) Institutional sources of change in the formal structure of organizations: the diffusion of civil service reform, 1880-1935. Administrative Science Quarterly, $28(1), 22-39$.

Walker, H. A. (2004) Bevond power and domination: legitimacy and formal organizations. In: Research in the Sociology of Organizations, 22, 239-271.

Weber, M. (1978) Economy and society. Berkeley: University of California Press.

Williamson, O. E. (1975) Corporate control and business behavior: an inquiry into the effects of organizational form on enterprise behavior. Englewood Cliffs, NJ: Prentice Hall.

Zelditch, M. (2001) Process of legitimation: recent developments and new directions. Social Psychology Quarterly, 64 (1), 4-17.

Zelditch, M., \& Floyd, A. S. (1998) Consensus, dissensus, and justification. Status, power, and legitimacy: Strategies and theories, 339-368.

Zucker, L. G. (1977) The role of institutionalization in cultural persistence. American Sociological Review, 42 (5), 726-743.

Recebido em: 06/02/2015

Publicado em: 04/08/2015 